\title{
Effects of copper on leaf membrane structure and root activity of maize seedling
}

Jiao Jiao Liu ${ }^{1 \dagger}$, Zhen $\mathrm{Wei}^{2+}$ and Jia Hui $\mathrm{Li}^{2^{*+}}$

\begin{abstract}
Background: Copper is an important heavy metal pollutant, with strong toxicity and great harm, which is easy to accumulate in the plant body and is difficult for degradation. This paper adopts medium culture method, taking "Zheng Dan 958" maize seedlings as sample materials. With different copper ion concentration gradients for the simulation of metal copper stress on maize seedlings, it explored the effects on the membrane structure (POD activity, MDA content, membrane permeability) and root activity.

Results: POD activity increases dramatically when the copper concentration is over $10 \mu \mathrm{mol} / \mathrm{L}$. MDA content increases sharply when the copper concentration is over $1000 \mu \mathrm{mol} / \mathrm{L}$, showing a rising trend. Membrane permeability increases greatly when the copper concentration is over $100 \mu \mathrm{mol} / \mathrm{L}$. Root activity decreases significantly when the copper concentration is $100 \mu \mathrm{mol} / \mathrm{L}$, showing a clear downward trend.

Conclusions: The copper concentration of $1000 \mu \mathrm{mol} / \mathrm{L}$ has exceeded the maize seedling tolerance to copper, and the activities of protective enzymes of maize seedlings are inhibited. Cell membrane lipid peroxidation has caused serious damage on the structure and function of membrane. Structure of root cells of maize seedling is also damaged, reducing the root activity, so the maize is irreversible hurt.
\end{abstract}

Keywords: Copper; Maize; Membrane structure; Root activity

\section{Background}

Heavy metals are main pollutants, which have potential harm on the environment. Along with the development of industry, heavy metal pollution has become a serious problem. Copper mining, discharge of the three wastes of smelting plant, agricultural chemicals containing copper and the discharge of domestic sewage, the soil copper content is several times of the original content in soil (Besnard et al. 2001; Brun et al. 2001). Copper pollution has become a worldwide problem in recent years: copper is not degraded by microorganisms in the soil, so it is generally difficult to eliminate the pollution; the high rate of copper residue in the soil can cause many serious problems to the environment and human health; copper is an important heavy metal pollutant, with strong toxicity and great harm, which is easy to accumulate in the plant body and is difficult for degradation. Copper pollution problem has aroused extensive attention.

\footnotetext{
*Correspondence: lijiahui_tony@163.com

${ }^{\dagger}$ Equal contributors

${ }^{2}$ No.2 Secondary School Attached to East China Normal University, No.555,

Chenhui Rd, Shanghai 201203, China

Full list of author information is available at the end of the article
}

However, copper has played an important role on plant physiological metabolism: as one of the 9 kinds of trace elements in plants which are necessary to normal life activities, copper is a part of oxidoreductase (such as polyphenol oxidase, cytochrome oxidase, ascorbic acid oxidase), the lack of copper will directly affect the metabolism of plant in the process of growth and development. But copper has a cumulative nature (Chang et al. 2000); plants' absorption of copper ions will be fixed in the root cortex, affecting the absorption of other nutrients. Excessive copper will produce toxic effects to plants, facilitating the formation of reactive oxygen species, causing cell oxidative damage and increasing membrane permeability (Kong et al. 1999; Zhang et al. 1997, 2006; Reboredo and Henriques 1991; Eleftheriou and Karataglis 1989; Madejonb et al. 2009), which will change plant antioxidative enzyme system (Scandalous 1993).

Maize (Zea mays L.) belongs to Maydeae group of Poaceae family, which is widely distributed in China. It is one of the main foods of people in North China, Southwest Mountain and other dry Gulch area. Many scholars have studied the physiological and ecological 
effects of different heavy metals on maize. Kong et al. (1999) studied on the change of permeability and protective enzyme activity of maize seedlings cell membrane under $\mathrm{Cd}^{2+}$ stress (Kong et al. 1999). The results showed that with the increase of cadmium concentration, POD activity, MDA content and the membrane permeability increased, the growth of the seedlings was inhibited. Zhang et al. (1997) conducted the hydroponics experiment to study the effects of $\mathrm{Hg}^{2+}$ on the oxidative defense system of maize seedlings lipid (Zhang et al. 2006). Results showed that: after $\mathrm{Hg}^{2+}$ treatment, maize leaves membrane permeability and MDA content increased significantly; the activity of POD significantly decreased. By nutrient solution culture experiment, Zhang et al. (2006) studied root vigor and activity of antioxidant enzymes of different varieties of maize seedling stressed by $\mathrm{Pb}^{2+}$ (Zhang et al. 1997). Results showed that: under the impact of $\mathrm{Pb}^{2+}$, root vigor decreased. $\mathrm{As}^{\mathrm{Pb}^{2+}}$ concentration increasing, POD activity was increased and then decreased. However, the stress effect of heavy metal copper on maize membrane structure and root activity has not been reported.

This paper adopts medium culture method, taking "Zheng Dan 958" maize seedlings as sample materials. With different copper ion concentration gradients $(0,1$, $10,100,1000,5000,10000 \mu \mathrm{mol} / \mathrm{L}$ ) for the simulation of metal copper stress on maize seedlings, it explored the effects on the membrane structure (POD activity, MDA content, membrane permeability) and root activity. It reveals the effect of copper stress in maize, which will provide certain theory reference for the agricultural production and rational application of trace element copper.

\section{Methods \\ Materials}

Tested material is "Zheng Dan 958" maize. Select plump and uniform maize seeds, after $0.2 \% \mathrm{~K}_{2} \mathrm{MnO}_{4}$ immersion disinfection of $20 \mathrm{~min}$, wash with clean water for several times, put into the digital electric incubator in distilled water for $8 \mathrm{~h}$. The temperature of the incubator is set at $30^{\circ} \mathrm{C}$. Soaked seeds are planted in pots containing an equal amount of vermiculite, which is wet with distilled water. Keep the fixed seed spacing and embryo direction when planting, with 30 seeds in one basin and a total of 28 basins. Put a layer of dry vermiculite in each basin. After planting, put basins into light incubator (without illumination, temperature of $25^{\circ} \mathrm{C}$ ) in culture. Turn on the light after $2 \mathrm{~d}$ in the 4 level of light intensity (2 time intervals a day, total $14 \mathrm{~h}$ under illumination) and timely pour distilled water. After $7 \mathrm{~d}$, select 15 seedlings of uniform growth. Keep culturing in light incubator and conduct copper stress processing after $4 \mathrm{~d}$.
Use $\mathrm{CuSO}_{4} \cdot 5 \mathrm{H}_{2} \mathrm{O}$ (A. R.) to make Hoagland culture medium of different copper concentrations: $0,1,10,100$, 1000, 5000, $10000 \mu \mathrm{mol} / \mathrm{L}$, pour equivalent Hoagland medium of different copper concentrations on plants (each treatment has 4 replicates) and label them, culture for $12 \mathrm{~d}$ and pour medium for 3 times. 12d later, measure each physiological index.

\section{Test methods}

\section{Peroxidase (POD) activity determination}

According to the literature (Zhang et al. 2000), take $0.2 \mathrm{~g}$ tested plant materials leaves treated with different concentrations of copper, chop into a mortar, add a little quartz sand and solution of $2 \mathrm{~mL} 20 \mathrm{mmol} / \mathrm{L} \mathrm{KH}_{2} \mathrm{PO}_{4}$ into the mortar; grind into homogenate, put it into a centrifuge tube. Then add $3 \mathrm{~mL} 20 \mathrm{mmol} / \mathrm{L} \mathrm{KH}_{2} \mathrm{KO}_{4}$ solutions to rinse the mortar, put the solution into a centrifuge tube $(4000 \mathrm{r} / \mathrm{min}$ centrifugal for $15 \mathrm{~min}$ ). Supernatant is collected and preserved in the cold. Extract

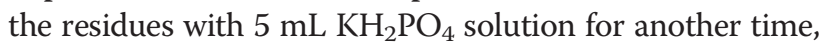
merge the two supernatant. The $3 \mathrm{~mL}$ reaction mixture $(50 \mathrm{~mL} 100 \mathrm{mmol} / \mathrm{L} \mathrm{pH}=6.0$ phosphate buffer; $19 \mu \mathrm{L}$ $30 \% \mathrm{H}_{2} \mathrm{O}_{2} ; 28 \mu \mathrm{L}$ guaiacol) and $1 \mathrm{~mL}$ enzyme are add in the cuvette for the determination of enzyme activity. Meanwhile, $3 \mathrm{~mL}$ reaction mixed solution and $1 \mathrm{~mL}$ $\mathrm{KH}_{2} \mathrm{PO}_{4}$ solution is the control group. Immediately turn on the stopwatch, measure OD at the spectrophotometer $470 \mathrm{~nm}$ wavelength; read OD value every minute. OD value changes indicate that the enzyme activity, which is represented by $\Delta \mathrm{A}_{470} /[\mathrm{min} \cdot \mathrm{FW}(\mathrm{g})]$.

\section{Malondialdehyde (MDA) content determination}

Take $0.3 \mathrm{~g}$ tested plant materials leaves treated with different concentrations of copper, chop into a mortar, add $2 \mathrm{~mL} \mathrm{10 \%} \mathrm{TCA} \mathrm{and} \mathrm{a} \mathrm{small} \mathrm{amount} \mathrm{of} \mathrm{quartz} \mathrm{sand,}$ grind into homogenate and pour into the centrifugal tube, add $6 \mathrm{~mL}$ TCA to rinse mortar, put the solution into a centrifuge tube (4000 r/min centrifugal for $10 \mathrm{~min}$ ), supernatant is extracted as sample. Take $2 \mathrm{~mL}$ extract, add into $2 \mathrm{~mL} 0.6 \%$ TBA solution, mix and plug in the tube, seal with plastic wrap, place in boiling water for $30 \mathrm{~min}$ and then cool it rapidly. The supernatant is taken for the determination of OD value at $532 \mathrm{~nm}$ and $450 \mathrm{~nm}$. The control group is the TCA solution. According to the formula $C(\mu \mathrm{mol} / \mathrm{L})=6.45 \times A_{532}-0.56 \times A_{450}$, calculate the MDA concentration, then calculate the content of MDA per gram $(\mu \mathrm{mol} / \mathrm{g})$.

\section{Membrane permeability determination}

Take $1.0 \mathrm{~g}$ tested plant leaf treated by different concentrations, put into a small triangle flask, add $20 \mathrm{~mL}$ distilled water, seal with plastic wrap, shake so that leaves are all immersed in distilled water, stand for $3 \mathrm{~h}$ at room temperature, measure the electrical conductance value 
$\left(S_{1}\right)$. Then it is placed in boiling water for $20 \mathrm{~min}$, cool and measure the conductance value $\left(S_{2}\right)$, measure the electrical conductance value of distilled water $\left(S_{3}\right)$. Use $\frac{S_{1}-S_{3}}{S_{2}-S_{3}} \times 100 \%$ to express the relative membrane permeability (\%).

\section{Root activity determination}

Prepare 0, 0.005\%, 0.01\%, 0.02\%, 0.03\%, 0.04\% TTC solution, take $5 \mathrm{~mL}$ of each into graduated test tubes, take $5 \mathrm{~mL}$ ethyl acetate and a small amount of $\mathrm{Na}_{2} \mathrm{~S}_{2} \mathrm{O}_{4}$ (approximately $2 \mathrm{mg}$, same quantity in each tube), shake sufficiently to produce red TTF, transfer to the ethyl acetate layer; after the colored liquid separation, add $5 \mathrm{~mL}$ of ethyl acetate, shake and rest, take the upper ethyl acetate solution, with a blank as the reference, to determine OD of the solution in the spectrophotometer $485 \mathrm{~nm}$, then with TTC concentration as the abscissa, OD as ordinate, draw standard curve. TTC standard curve is $y=0.001 x+0.0034$.

Take $0.5 \mathrm{~g}$ plant root samples treated by different concentrations of copper; immerse in $10 \mathrm{~mL}$ beaker with the mixed liquid of $0.4 \% \mathrm{TTC}$ and $66 \mathrm{mmol} / \mathrm{L}$ phosphate buffer solution $\left(\mathrm{pH}=7.0\right.$ ), keep at $37^{\circ} \mathrm{C}$ for $3 \mathrm{~h}$, then add $1 \mathrm{~mol} / \mathrm{L}$ of sulfuric acid $2 \mathrm{~mL}$ to terminate reaction. Remove the root, carefully wipe it and grind with $2 \mathrm{~mL}$ ethyl acetate and a small amount of quartz sand in a mortar to extract TTF, use a small amount of ethyl acetate to wash the residue for $2 \sim 3$ times, then pour into the test tube, finally add the ethyl acetate to scale, use a spectrophotometer for $485 \mathrm{~nm}$ colorimetry, taking the blank test (with sulfuric acid, then add the root samples) as reference, readout the OD. According to the standard curve of $y=0.001 x+0.0034$, the reducing amount of TTC can be obtained. According to the reduction amount of TTC, we can get the reducing strength of TTC.

$$
\begin{aligned}
& \text { Reducing Strength of TTC } \\
& =\frac{\text { Reduction Amount of TTC }(\mathrm{mg})}{\text { Weight of Root Sample }(\mathrm{g}) \times \text { Time }(\mathrm{h})}
\end{aligned}
$$

\section{Results and discussion}

Influence of peroxidase (POD) activity of copper stress on maize seedling leaf

A lot of researches show that the essence of damage of membrane structure is a process of membrane lipid peroxidation. Lipid peroxidation is the harmful reaction of biological free radical (mainly active oxygen) on unsaturated fatty acid and some protective enzyme system can clean harmful reactive oxygen species (ROS) (Chen 1989, 1991). POD is an important protective enzyme of plant defense against membrane lipid peroxidation, which is an important enzyme to clean $\mathrm{H}_{2} \mathrm{O}_{2}$ and many organic hydroperoxides. In the organization with little number of catalase content or low $\mathrm{H}_{2} \mathrm{O}_{2}$ content, it can replace the catalase peroxidase to eliminate $\mathrm{H}_{2} \mathrm{O}_{2}$ (Reddy et al. 2005) and its activity can reflect the toxic symptoms of plant. Figure 1 shows that: with the deepening degree of copper stress, POD activity increases slowly. Under the copper concentrations of $1 \mu \mathrm{mol} / \mathrm{L}$ and $10 \mu \mathrm{mol} / \mathrm{L}$, the gap of POD activity and control group is not big, which increases by $2 \%$ and $4.5 \%$. The toxic level of maize seedlings is not high. The body produces reactive little oxygen. But when the copper concentration is over $10 \mu \mathrm{mol} / \mathrm{L}$, POD activity increases dramatically. When the copper concentration is $100 \mu \mathrm{mol} / \mathrm{L}$, POD activity is the biggest, increases by $26.8 \%$ than the control. When the maize seedlings are under the high concentrations of copper stress, the injured degree aggravates, the body produces more active oxygen and the seedlings make positive protection. The antioxidant capacity of maize seedlings increases because of adaption. $\mathrm{H}_{2} \mathrm{O}_{2}$ is deposed into $\mathrm{H}_{2} \mathrm{O}$ to resist the poison.

\section{Influence of malondialdehyde (MDA) content of copper stress on maize seedling leaf}

Copper stress results in large numbers of active oxygen free radicals in leaves of maize seedlings, causing cell membrane lipid peroxidation, damaging the normal structure and function of the membrane. MDA is one of the products of cell membrane lipid peroxidation, the combination of MDA and protein can cause protein intramolecular and intermolecular cross-link, which will seriously damage the biomembrane. Its content can react the level of cell membrane lipid peroxidation and the damage degree of cell membrane reaction. MDA content changes are often taken as the parameter of lipid peroxidation of cell membrane under adversity. Figure 2 shows: with the deepening degree of copper stress, MDA content first increases gradually before the trend. When the copper concentration reaches $1000 \mu \mathrm{mol} / \mathrm{L}, \mathrm{MDA}$ content has little difference compared with control group, when the copper concentrations are 1, 10, 100,

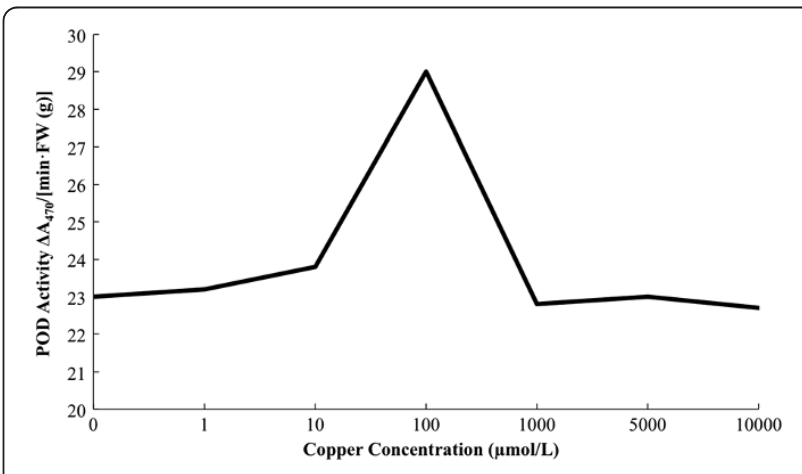

Figure 1 Influence of POD activity of copper stress on maize seedling leaf. 


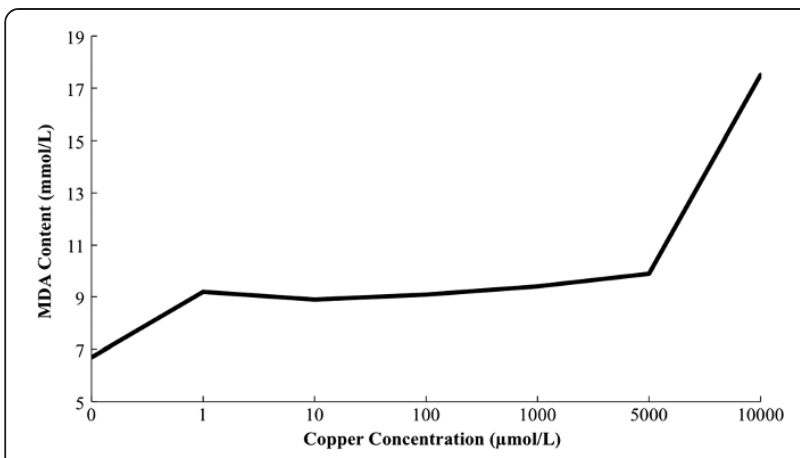

Figure $\mathbf{2}$ Influence of MDA content of copper stress on maize seedling leaf.

$1000 \mu \mathrm{mol} / \mathrm{L}$, MDA content increases by $15.5 \%, 10.7 \%$, $12.8 \%$ and $12.6 \%$. That shows the low level of damage of cell membrane lipid peroxidation on cell membrane. When the copper concentration is $1000 \mu \mathrm{mol} / \mathrm{L}, \mathrm{MDA}$ content increases sharply. When the copper concentrations are at $5000 \mu \mathrm{mol} / \mathrm{L}$ and $10000 \mu \mathrm{mol} / \mathrm{L}$, MDA content increases by $42.6 \%$ and $144.4 \%$, respectively. That means the high concentrations of copper stress can cause significant damage to the structure and function of cell membrane. Leaves produce oxidative stress, lipid peroxidation of cell membrane increases, MDA and other harmful products of membrane lipid peroxidation are produced, which may be an important mechanism of copper stress on plant growth.

\section{Influence of membrane permeability of copper stress on maize seedling leaf}

Cell membrane is selectively permeable membrane, which can control and adjust the transport and exchange of intracellular substances. At the cellular level, it is the first site of stress injury. The permeability values reflect the amount of soluble substance leakage within the cell membrane, so is the evaluation index of the reaction of plants to environmental damage. Copper stress' most direct harm to the plant cell is the structure and function of cell membrane, with the membrane permeability increases, membrane stability decreases, passive leakage of ion cells and macromolecules. Therefore, the increased membrane penetrability is the direct evidence of cell membrane damage.

Figure 3 shows that: with the deepening degree of copper stress, electrolyte leakage rate of maize seedlings increases slowly. Before the copper concentration reaches $100 \mu \mathrm{mol} / \mathrm{L}$, membrane permeability changes little compared with control group. When the copper concentrations are 1, 10, and $100 \mu \mathrm{mol} / \mathrm{L}$, membrane permeability increases by $1.9 \%, 4.1 \%$ and $1.3 \%$, respectively. The structure and function of cell membrane have not yet been damaged. But when the copper concentration is over $100 \mu \mathrm{mol} / \mathrm{L}$, membrane permeability increases

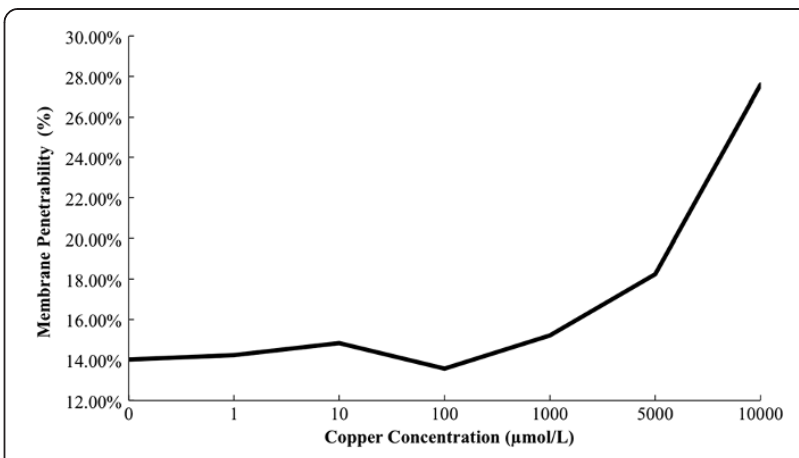

Figure 3 Influence of membrane permeability of copper stress on maize seedling.

rapidly, which shows a rising trend. When copper concentrations are $1000 \mu \mathrm{mol} / \mathrm{L}, 5000 \mu \mathrm{mol} / \mathrm{L}$ and $10000 \mu \mathrm{mol} / \mathrm{L}$, membrane permeability increases by $19.5 \%, 47.1 \%$ and $104.8 \%$, respectively. That means the high concentrations of copper stress can damage the structure and function of cell membrane in leaves of maize seedlings severely, promoting the electrolyte leakage.

Figure 3 also shows that although the change pattern of leaf MDA content and membrane permeability increases slowly at first and then increases sharply, the increasing amplitude is different. For membrane permeability, when the copper concentration is $1000 \mu \mathrm{mol} / \mathrm{L}$, it increases significantly by $19.5 \%$ than that of the control group. For MDA content, when the copper concentration is $5000 \mu \mathrm{mol} / \mathrm{L}$, it increases significantly by $42.6 \%$. That means there are many factors causing the damage of cell membrane. Cell membrane lipid peroxidation is just one aspect. Certainly there are other factors leading to the increase of membrane permeability. Maybe copper, destroying the structure and function of membrane, due to membrane protein inactivation and degeneration causes it.

\section{Influence of root activity of copper stress on maize seedling leaf}

Heavy metal pollutants can directly affect plant roots, while root activity can reflect the quality and metabolic status of root development in a certain extent, so the activity of root can be used to measure the degree of injury of root.

Figure 4 shows that: copper stress damage on the root of maize seedling appears earlier. It is visible that root is the worst part of heavy metal stress. When the copper concentration is $1 \mu \mathrm{mol} / \mathrm{L}$, the root activity begins to decrease by $18.3 \%$. When the copper concentration is $10 \mu \mathrm{mol} / \mathrm{L}$, it reduces to the maximum level, decreases by $62.7 \%$ comparing to the control group, which means that maize seedling roots have suffered serious damage. When copper concentration is $100 \mu \mathrm{mol} / \mathrm{L}$, with increasing concentration, root activity decreases slowly. 


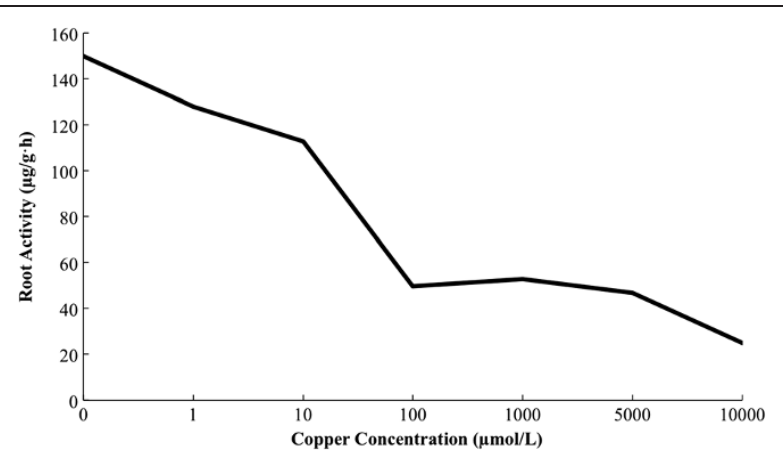

Figure 4 Influence of root activity of copper stress on maize seedling leaf.

\section{Conclusion}

Copper is one of essential trace element for normal growth and development of plants, which takes part in various biochemical and physiological process in plant (Sudo et al. 2008; Burkhead et al. 2009). However, excessive copper can be toxic to plant cells, or even lead to cell death. An important feature of copper toxicity to plants is to produce oxidative stress, leading to the formation of harmful ROS. Under normal conditions, plants can effectively clean out ROS, protecting cells from damage. But in the face of adversity condition, when ROS is produced faster than the ability of plants to scavenge active oxygen, it will cause the damage (Li and Mei 1989; Elastner 1982; Chris et al. 1992). POD can clear harmful reactive oxygen species, so as to protect the membrane system. Under the condition of this experiment, with the increasing of copper concentration, POD activity increases slowly. Before the copper concentration reaches $10 \mu \mathrm{mol} / \mathrm{L}$, POD activity changes little relative to control group. But when the copper concentration is over $10 \mu \mathrm{mol} / \mathrm{L}$, POD activity increases dramatically; when the copper concentration is up to $100 \mu \mathrm{mol} / \mathrm{L}, \mathrm{POD}$ activity is the highest. Increased peroxidase activity is the stress response of plants, indicating that $100 \mu \mathrm{mol} / \mathrm{L}$ is the harmful concentrations on maize growth.

The plant cell membrane system is the interface and barrier for exchange of substance and information exchange of plant and environment, which plays an important role in maintaining cell microenvironments and normal metabolism. Its stability is the basic of normal physiological function. The copper stress can induce cell membrane lipid peroxidation and membrane structure and functional damage. Malondialdehyde (MDA) is one of the products of the cell membrane lipid peroxidation. Its content can reflect the degree of cell membrane lipid and membrane oxidative damage. It is found in the present study, when the copper concentration is over $1000 \mu \mathrm{mol} / \mathrm{L}, \mathrm{MDA}$ content increases sharply, which shows a rising trend.
Copper toxicity-induced ROS directly or indirectly can attack the protein, lipid and other biological macromolecules, causing oxidation or degradation, leading to the increase of biological membrane permeability (Sharma and Dietz 2009) and the stress intensity is related to the degree of increase of membrane permeability. Under the experimental condition, when the copper concentration is over $100 \mu \mathrm{mol} / \mathrm{L}$, membrane permeability increases sharply. Under copper concentration $\geq 100 \mu \mathrm{mol} / \mathrm{L}$, cell plasma membrane damage of maize seedling leaf is very serious.

Maize root is exposed to the damage of heavy metal firstly in the whole plant. It is also under the worst influence of copper stress. After root cell membrane being hurt, intracellular ion and organic substance leak greatly. External $\mathrm{Cu}^{2+}$ would take the opportunity to enter the cell, resulting in physiological metabolism disorder (Jiang and Zhao 2001). It can be seen from the results of this study: Copper Stress has obvious effects on physiological and biochemical characteristics of maize seedling roots. When the copper concentration is $100 \mu \mathrm{mol} / \mathrm{L}$, maize root activity decreases significantly, showing a clear downward trend. In addition, we can also infer that with deeper damage to maize roots, its absorptive capacity will continue to decrease, which will lead to plant aboveground nutrient deficiency and further accelerate the physiological metabolism disorder.

According to the variation curve of POD activity, MDA content, membrane permeability and root activity of maize seedlings under copper stress, the copper concentration of $1000 \mu \mathrm{mol} / \mathrm{L}$ is beyond the tolerance limit of maize seedlings. The activity of protective enzymes of maize seedlings is inhibited. Cell membrane is under serious lipid peroxidation, which damages the structure and function of membrane. Structure of root cells of maize seedling is damaged, reducing the root activity. Maize seedlings are under irreversible damage.

\section{Competing interests}

The authors declare that they have no competing interests.

\section{Authors' contributions}

$J H L$ carried out the experiment. JJL, ZW \& JHL designed the experiment and drafted the manuscript. All the authors read and approved the final manuscript.

\section{Author details}

'School of Life Sciences of East China Normal University, No.500, Dongchuan Rd, Shanghai 200241, China. ${ }^{2}$ No.2 Secondary School Attached to East China Normal University, No.555, Chenhui Rd, Shanghai 201203, China.

Received: 9 April 2014 Accepted: 2 May 2014

Published online: 27 May 2014

\section{References}

Besnard E, Chenu C, Robert M (2001) Influence of organic amendments on copper distribution among particle-size and density fraction in champagne vineyard soils. Environ Pollut 112(3):329-337 
Brun A, Maillet J, Hinsinger P, Pépina M (2001) Evaluation of copper availability to plants in copper-contaminated vineyard soils. Environ Pollut 111(2):293-302

Burkhead L, Gogolin AR, Ghany EA (2009) Copper homeostasis. New Phytol 182:799-816

Chang HY, Sun BY, Liu CS (2000) Advances in the study of plants copper toxicity. J Shandong Agr Univ (Nat Sci) 31(2):227-230

Chen SY (1989) Membrane-lipid peroxidation and plant stress. Chinese Bull Bot 6(4):211-217

Chen SY (1991) Injury of membrane-lipid peroxidation to plant cell. Plant Physiol Commun 27(2):84-89

Chris B, Marc H, Dirk I (1992) Superoxide dismutase and stress tolerance. Annu Rev Plant Pysiol Plant Mol Biol 43:83-116

Elastner F (1982) Oxygen activation and oxygen toxicity. Ann Rev Plant Physiol 33:73-96

Eleftheriou EP, Karataglis S (1989) Ultra-structural and morphological characteristics of cultivated wheat growing on copper-polluted fields. Bot Acta 102:134-140

Jiang XY, Zhao KF (2001) Mechanism of heavy metal injury and resistances of plants. China J Appl Environ Biol 7(1):91-99

Kong XS, Guo XP, Zhang MX (1999) Effect of cadmium stress on seedling growth and physiology- chemistry of maize. J Huazhong Agr Univ 18(2):111-113

Li BL, Mei HS (1989) Relationship between oat leaf senescence and activated oxygen metabolism. Acta Phyto Sin 15(1):6-12

Madejonb P, Ramirez-benitezc JE, Corralesa I, Barcelóa J, Poschenriedera C (2009) Copper-induced oxidative damage and enhanced antioxidant defenses in the root apex of maize cultivars differing in Cu tolerance. Environ Exp Bot 67(2):415-420

Reboredo F, Henriques F (1991) Some observations on the leaf ultrastructure of Halimioneportulacaides (L.) Aellengrown in a medium containing copper. J Plant Physiol 137:717-722

Reddy MA, Kumar SG, Jyothsnakumari G, Thimmanaikc S, Sudhakarc C (2005) Lead induced changes in antioxidant metabolism of horse gram (Macrotylomauniflorum (Lam.) Verdc.) and Bengal gram (Cicerarietinum L.). Chemosphere 60(1):97-104

Scandalous G (1993) Oxygen stress and superoxide dismattoses. Plant Physiol 101(1):7-13

Sharma S, Dietz J (2009) The relationship between metal toxicity and cellular redox imbalance. Trends Plant Sci 14(1):43-50

Sudo E, Itouga M, Yoshida-Hatanaka K, Ono Y, Sakakibara H (2008) Gene expression and sensitivity in response to copper stress in rice leaves. J Exp Bot 59(12):3465-3474

Zhang X, Bu YH, Wang XD (1997) Effects of $\mathrm{Hg}^{2+}$ on the Protective System of Membrane- Lipid Peroxidation in Maize Seedling. J Henan Univ (Nat Sci) 27(1):77-80

Zhang ZL, Qu WJ, Li XF (2000) Plant Physiol Exp (Fourth Edition).

Zhang LH, Li XM, Cheng Q, He XY (2006) Effects of lead on antioxidant enzymes and root activities among maize cultivars. J Jilin Agr Univ (Nat Sci) 28(2):119-122

doi:10.1186/s40529-014-0047-5

Cite this article as: Liu et al:: Effects of copper on leaf membrane structure and root activity of maize seedling. Botanical Studies 2014 55:47.

\section{Submit your manuscript to a SpringerOpen ${ }^{\odot}$ journal and benefit from:}

- Convenient online submission

- Rigorous peer review

- Immediate publication on acceptance

- Open access: articles freely available online

- High visibility within the field

- Retaining the copyright to your article

Submit your next manuscript at $\gg$ springeropen.com 